cases and 210 controls) were analysed regarding phenotypic characteristics for risk of melanoma as well as number of grandparents born in Europe. European ancestry (Spanish, Italian, Germanic or Slavic, and 2 or more European country), eye colour (light brown and green or blue), presence of nevi, use of sunscreen, referred episodes of sunburn in adolescence or not, were independently associated with melanoma. Portuguese ancestry was not associated in multivariate logistic regression analysis. Our data confirmed the importance of European ancestry as a susceptibility factor. The higher tendency to develop melanoma in persons with those ancestries could be related not only to the phenotypic but probably also to other genetic characteristics.

\section{P2-443 A RETROSPECTIVE EPIDEMIOLOGICAL STUDY OF ENDEMIC WATERBORNE ILLNESS IN A PASTORAL COMMUNITY IN KENYA}

doi:10.1136/jech.2011.142976l.73

${ }^{1} \mathrm{P}$ Macharia, ${ }^{2} \mathrm{P}$ Yillia, ${ }^{3} \mathrm{D}$ Byamukama, ${ }^{1} \mathrm{~W}$ Muia, ${ }^{2} \mathrm{~N}$ Kreuzinger. ${ }^{1}$ Egerton University, Department of Biological Sciences, Egerton, Kenya; ${ }^{2}$ Vienna University of Technology, Institute for Water Quality \& Waste Management, Vienna, Austria; ${ }^{3}$ WSS Services (U) Ltd, Kampala, Uganda

Case-patients for a retrospective epidemiological cum microbiological study in Njoro Town, Kenya were selected after self-report of waterborne illness within 7 days of exposure through drinking water. Controls were matched for location, household income and type of drinking water source. Households with piped water in one highincome district reported considerably lower illness rates compared to unconnected households in two low-income districts. Analysis of the ORs identified water from the stream to be associated with the highest risk of illness $(\mathrm{OR}=3.95, \mathrm{p}=0.03)$ compared to untreated rainwater $(\mathrm{OR}=2.45, \mathrm{p}=0.02)$, untreated water from boreholes $(\mathrm{OR}=1.90$, $p=0.02)$ or treated water from any source $(O R=0.62, p=0.01)$. Bacteria densities in water obtained from the stream were generally 1-3 log units higher compared to other sources, staying within 3-4 $\log$ units for HPC (cfu/ml) and TC (cfu/100 ml), 2-3 log units (cfu/ $100 \mathrm{ml}$ ) for Escherichia coli and intestinal enterococci and within 1 log unit $(\mathrm{cfu} / 100 \mathrm{ml})$ for Salmonella. Several confounding risk factors other than contaminated water were identified. Their detection for over $50 \%$ of all illness cases was significant. It was concluded that the importance of drinking water quality as the most likely source of endemic waterborne illness in the community may have been previously overestimated. Therefore, interventions on water supply in the town should include strategies that address confounding risk factors, especially, poor hygiene and occupational hazards, as well as piped water distribution to low-income households.

\section{P2-444 INCIDENCE AND CORRELATES OF "GROWTH FALTERING" AMONG 0-6 YEAR'S CHILDREN: A PANEL STUDY FROM RURAL WARDHA, INDIA}

doi:10.1136/jech.2011.142976l.74

C Maliye, ${ }^{*}$ R Kumar, P Deshmukh, B Garg. Mahatma Gandhi Institute of Medical Sciences, Sevagram, Maharashtra, India

Objectives To study the magnitude and determinants of growth faltering among $0-6$ year's children in adopted villages of rural medical college.

Material and Methods A total 305 children of $<6$ years were followed monthly for 1 year to assess the growth faltering. At each visit, the mothers/caretaker of children were interviewed and information regarding immunisation, morbidity profile, dietary history and child feeding practices collected using a pre-tested interview schedule. Monthly anthropometric measurements of child were taken.
Growth faltering has been defined as failure to gain weight or actual loss of weight, and weight gain $<300 \mathrm{~g}$ over a period of three consecutive months.

Results The cumulative incidence of growth faltering among 0-6 years children was 930 per 1000 children per year (95\% CI 900.8 to 959.2). The number of growth faltering episodes per child per year was 3.1 (95\% CI 2.9 to 3.3). In the multivariate analysis we found presence of anaemia, presence of any illness \& improper household ventilation as significant predictors of growth faltering. Conclusion Our finding suggests more focus should be given on early detection and timely correction of growth faltering rather than just identification and treatment of severely malnourished children.

\section{P2-445 MATERNAL RISK FACTORS ASSOCIATED WITH LOW BIRTH WEIGHT IN WARDHA, INDIA}

doi:10.1136/jech.2011.142976l.75

C Maliye, ${ }^{*}$ M Taywade, S Gupta, P Deshmukh, B Garg. Mahatma Gandhi Institute of Medical Sciences, Sevagram, Maharashtra, India

Objective To evaluate the maternal risk factors associated with low birth weight.

Material and Methods A case control study was carried out on 307 cases (mothers of neonate weighing $<2500 \mathrm{~g}$ ) and 307 controls (mothers of neonate weighing $\geq 2500 \mathrm{~g}$ ) in District Hospital Wardha. Information was obtained by maternal interview, from medical records and by anthropometric measurement of mother and infants.

Data entry and Analysis The data entry and analysis was done in EpiInfo 6.04. OR was calculated to find out the association of various factors under study with low birth weight.

Results Among various determinants of low birth weight studied, the determinants which were found associated with high odds of LBW were - maternal age $<20$ years or $>30$ years, maternal weight $<40 \mathrm{~kg}$, gestational weight gain of less than $6 \mathrm{~kg}, \mathrm{BMI}<18.5 \mathrm{~kg} / \mathrm{m}^{2}$ and MUAC $<23 \mathrm{~cm}$, previous history of giving birth to LBW babies, maternal anaemia.

Conclusion Significant determinants of LBW were maternal age $<20$ years or $>30$ years, maternal weight $<40 \mathrm{~kg}$, gestational weight gain of less than $6 \mathrm{~kg}, \mathrm{BMI}<18.5 \mathrm{~kg} / \mathrm{m}^{2}$ and $\mathrm{MUAC}<23 \mathrm{~cm}$, previous history of giving birth to LBW babies, maternal anaemia.

\section{P2-446 WITHDRAWN}

\section{P2-447 RISK FACTORS OF MULTI-DRUG RESISTANT TUBERCULOSIS (MDR TB) IN NEPAL}

doi:10.1136/jech.2011.142976l.76

${ }^{1} \mathrm{~S}$ B Marahatta, ${ }^{*}{ }^{2} \mathrm{~J}$ Kaewkungwal, ${ }^{2} \mathrm{P}$ Ramasoota, ${ }^{2} \mathrm{P}$ Singhasivanon. ${ }^{1}$ Kathmandu University School of Medical Sciences, Dhulikhel, Nepal; ${ }^{2}$ Faculty of Tropical Medicine Mahidol University, Bangkok, Thailand

Introduction Multi-drug resistant (MDR) tuberculosis is defined as disease caused by Mycobacterium tuberculosis with resistance to atleast two anti-tubercular drugs isoniazid and rifampicin. Recent surveillance data have revealed that prevalence of the drug resistant tuberculosis has risen to the highest rate ever recorded in the history. The most powerful predictor of the presence of MDR-TB is a history of treatment of TB. Shortage of drugs has been one of the most common reasons for the inadequacy of the initial anti-TB regimen, especially in resource poor settings.

Method A case control study was carried out to among diagnosed MDR TB cases and Non-MDR TB cases to explore the risk factors. A total of 55 cases and 55 controls were enrolled for the study from central Nepal. 